\title{
FAKTOR-FAKTOR MOTIVASI BELAJAR EKSTERNAL YANG MEMPENGARUHI HASIL BELAJAR MENGGAMBAR TEKNIK I
}

\author{
Viki Fauzi,..1*, Tuti Iriani², R. Eka Murtinugraha ${ }^{3}$ \\ ${ }^{1}$ Alumni Pendidikan Teknik Bangunan FT UNJ, Jakarta, Indonesia. \\ 2 Pendidikan Teknik Bangunan, FT UNJ, Jakarta, Indonesia. \\ 3 Pendidikan Teknik Bangunan, FT UNJ, Jakarta, Indonesia \\ ${ }^{*}$ Corresponding author:
}

\begin{abstract}
This study aims to find out about the factors that affect external motivation to learn the results of Drawing Techniques I learned in college students S1 Studies Program of Technical Education Building, State University of Jakarta. Place of this research was conducted at the Department of Civil Engineering, State University of Jakarta in OctoberDecember 2011.

In this study using survey method. The population in this study were students of S1 Studies Program of Technical Education Building Department of Civil Engineering Faculty of Engineering, State University of Jakarta of 2007, 2008, 2009, and 2010 as many as 262 students and a sample of 72 students who are determined using the calculation Yamane with sampling techniques using simple random sampling. The instrument used was a questionnaire for data capture factors external motivation to learn and value the learning outcomes data UAS for Engineering Drawing I. Reliability of the results obtained from the calculation of $r$ values for the factors of external motivation to learn at 0.935 .
\end{abstract}

Based on the research results can be concluded that there are factors that influence motivation to learn external learning outcomes Mechanical Drawing I. In sub-indicators to obtain a family concern that is the largest average value 3.78, and the lowest mean value contained in the sub-indicators campus environment that is equal to 2.95. Overall indicator of family environment to obtain a mean value of 3.51, an indicator of the campus environment to obtain a mean value of 3.32, and for community environmental indicators obtained average value of 3.48 .

Based on research results obtained that the family environment is a factor external motivation to learn the most dominant in affecting learning outcomes of Engineering Drawing I with a mean value of 3.78 .

Keywords: motivation, learning, achievement 


\section{PENDAHULUAN}

Keberhasilan siswa dalam kegiatan belajar secara formal akan tercermin dalam pencapaian hasil belajar pada setiap mata pelajaran yang diajarkan di sekolah. Hasil belajar memegang peranan yang penting karena akan menentukan lulus tidaknya proses belajar siswa pada suatu lembaga pendidikan. Hasil belajar juga akan menunjukkan sejauh mana kemampuan dan daya serap siswa terhadap materi yang telah diajarkan guru. Hal ini akan memberikan umpan balik bagi guru dalam rangka memperbaiki cara mengajar sehingga dapat meningkatkan capaian hasil belajar siswa di waktu yang akan datang.

Hasil belajar dikatakan sempurna apabila memenuhi tiga aspek yakni: kognitif, afektif dan psikomotor, sebaliknya dikatakan kurang memuaskan jika seseorang belum mampu memenuhi target dalam ketiga kriteria tersebut. Hasil belajar merupakan tolak ukur yang utama untuk mengetahui keberhasilan belajar seseorang. Seorang yang hasil belajarnya tinggi dapat dikatakan bahwa ia telah berhasil dalam belajar. Hasil belajar adalah tingkat pengetahuan sejauh mana anak terhadap materi yang diterima (Slameto 2003:73).

Menggambar Teknik I merupakan mata kuliah yang wajib ditempuh oleh seluruh mahasiswa jurusan teknik sipil Universitas Negeri Jakarta. Selain itu, mata kuliah Menggambar Teknik I adalah mata kuliah prerekuisit Menggambar Teknik II. Mata kuliah Menggambar Teknik I bertujuan agar mahasiswa mempunyai keterampilan menggunakan alat gambar manual yang baik dan benar serta mengaplikasikan pada pembuatan gambar-gambar kerja proyek bidang teknik sipil. Materi kuliah Menggambar Teknik I mencakup cara penggunaan alat gambar, huruf, garis, dan simbol-simbol pengetahuan gambar proyeksi dan perspektif, aplikasi gambar sambungan konstruksi pada bangunan dan gambar rencana bangunan sederhana (Buku Pedoman Akademik 2007-2010). Berdasarkan pengkajian hasil belajar Menggambar Teknik I memperlihatkan hasil belajar yang fluktuatif. Berikut ini adalah persentase nilai hasil belajar Menggambar Teknik I.

Tabel 1. Persentase Nilai Hasil Belajar Menggambar Teknik I

\begin{tabular}{|c|c|c|c|c|}
\hline & 2007 & 2008 & 2009 & 2010 \\
\hline $\mathrm{A}$ & $17 \%$ & $9 \%$ & $15 \%$ & $14 \%$ \\
\hline $\mathrm{B}$ & $69 \%$ & $63 \%$ & $66 \%$ & $64 \%$ \\
\hline $\mathrm{C}$ & $14 \%$ & $19 \%$ & $12 \%$ & $13 \%$ \\
\hline $\mathrm{D}$ & $0 \%$ & $4 \%$ & $2 \%$ & $0 \%$ \\
\hline $\mathrm{E}$ & $0 \%$ & $5 \%$ & $5 \%$ & $9 \%$ \\
\hline
\end{tabular}

Berdasarkan Tabel 1.1 terlihat bahwa hasil belajar Menggambar Teknik I dari angkatan 2007-2010 lebih dari 60\% memperoleh nilai $B$, yang berarti Baik. Namun disisi lain terdapat peningkatan jumlah mahasiswa yang tidak lulus atau memperoleh nilai E. Hal ini terlihat jelas pada mahasiswa angkatan 2007 sebanyak $0 \%$ mahasiswa yang memperolah nilai $\mathrm{E}$, kemudian meningkat menjadi 5\% mahasiswa pada mahasiswa 2008 dan 2009, lalu kembali meningkat 
menjadi 9\% mahasiswa pada angkatan 2010 yang memperoleh nilai $E$.

Hasil belajar yang dicapai mahasiswa tersebut mengindikasikan adanya kesulitan dalam memperoleh hasil belajar yang maksimal dalam mata kuliah Menggambar Teknik I. Hal ini dapat dipengaruhi oleh beberapa faktor. Motivasi belajar merupakan salah satu faktor yang dapat mempengaruhi hasil belajar Menggambar Teknik I. Adapun faktor-faktor yang mempengaruhi motivasi belajar mahasiswa adalah faktor motivasi belajar internal dan faktor motivasi belajar eksternal.

Faktor motivasi belajar internal adalah faktor motivasi belajar yang berasal dalam diri mahasiswa itu sendiri (minat, bakat, kesehatan dan lain-lain). Sedangkan faktor motivasi belajar eksternal yaitu faktor motivasi belajar yang berasal dari luar diri mahasiswa itu sendiri (lingkungan keluarga, linkungan masyarakat dan lingkungan tempat belajar). Dalam kajian Agustin (2008:80) menyatakan bahwa hasil belajar siswa dapat dipengaruhi oleh motivasi belajar. Faktor motivasi belajar eksternal mempengaruhi hasil belajar siswa sebesar $58,3 \%$, sedangkan sisanya $41,7 \%$ disebabkan oleh faktor lainnya. Agar tidak meluas, sesuai dengan kajian Agustin peneliti mencoba membatasi penelitian ini dengan hanya mendalami penelitian seputar faktor motivasi belajar eksternal.

Berdasarkan paparan diatas, maka peneliti akan mengkaji tentang faktorfaktor motivasi belajar eksternal apa sajakah yang mempengaruhi hasil belajar Menggambar Teknik I pada mahasiswa
Program Studi Pendidikan Teknik Bangunan Universitas Negeri Jakarta.

Tujuan penelitian adalah untuk mengetahui tentang faktor-faktor motivasi eksternal yang mempengaruhi hasil belajar menggambar teknik I pada mahasiswa Program Studi S1 Pendidikan Teknik Banguan Universitas Negeri Jakarta. Penelitian ini dilakukan di Fakultas Teknik Jurusan Teknik Sipil Universitas Negeri Jakarta. Waktu penelitian pada semester 095/ganjil tahun ajaran 2011/2012 pada bulan Oktober-Desember 2011.

\section{METODOLOGI PENELITIAN}

Metode yang digunakan dalam penelitian ini adalah metode penelitian survei. Hal tersebut untuk mengetahui adanya faktor-faktor motivasi eksternal yang mempengaruhi prestasi hasil belajar menggambar teknik I mahasiswa Program Studi S1 Pendidikan Teknik Banguan

\section{HASIL PENELITIAN DAN PEMBAHASAN}

\section{Hasil Penelitian}

Berdasarkan perhitungan data tentang faktor-faktor motivasi belajar eksternal yang mempengaruhi hasil belajar Menggambar Teknik I diketahui bahwa:

a. Nilai rerata lingkungan keluarga sebesar 3,51 dengan nilai rerata sub indikator perhatian keluarga sebesar 3,78, sarana dan pra sarana belajar menggambar di rumah sebesar 3,24.

b. Nilai rerata lingkungan kampus sebesar 3,32 dengan nilai rerata 
sub indikator cara dosen menyampaikan materi sebesar 3,24 , fasilitas menggambar di kampus sebesar 3,38 dan organisasi mahasiswa dikampus sebesar 3,43 c. Nilai rerata lingkungan masyarakat sebesar 3,48. Dengan nilai rerata sub indikator organisasi dimasyarakat sebesar 3,48 .
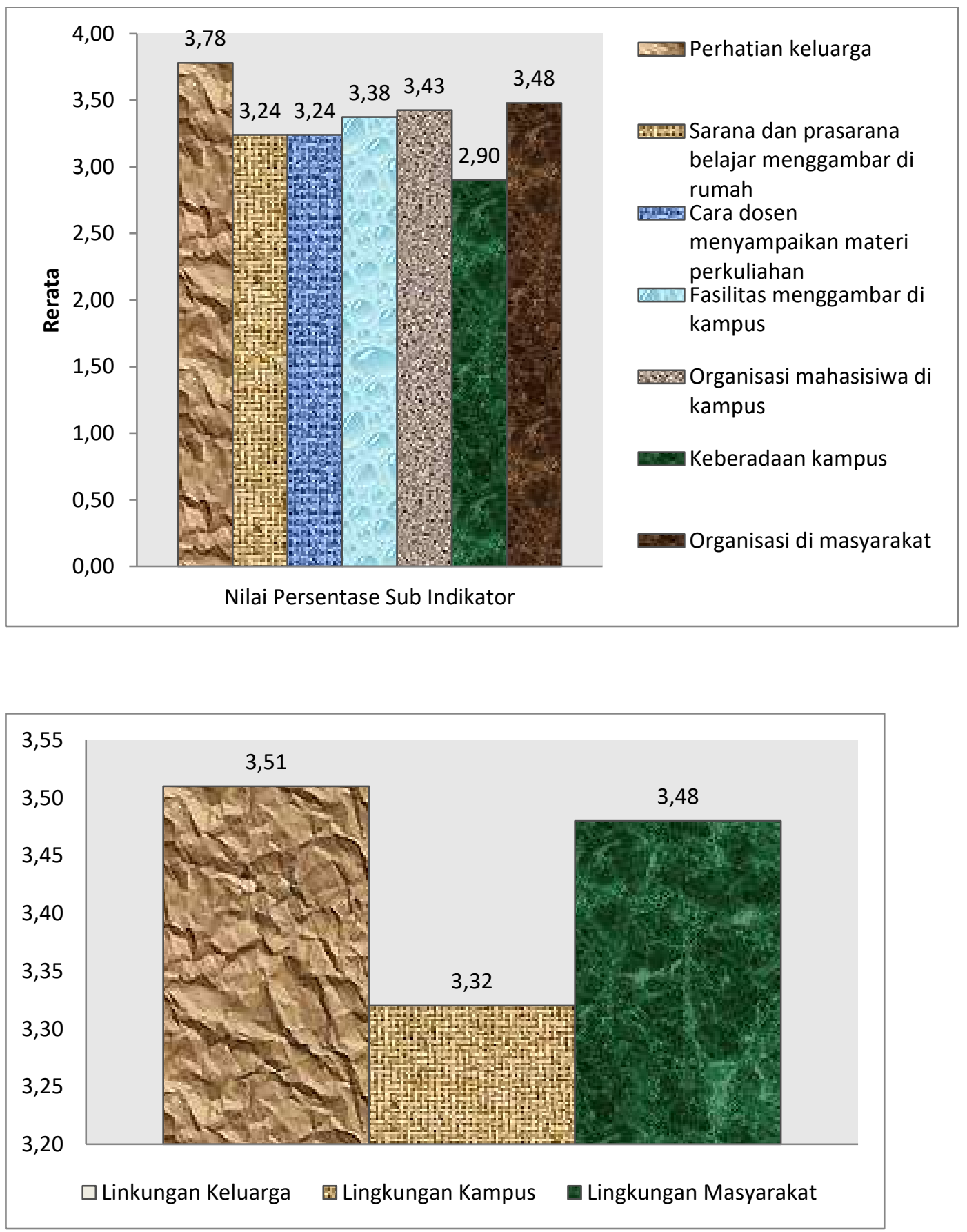


\section{Pembahasan}

Berdasarkan hasil penelitian dapat disimpulkan bahwa lingkungan keluarga, lingkungan kampus, dan lingkungan masyarakat dapat mempengaruhi hasil belajar Menggambar Teknik I. Lingkungan keluarga merupakan faktor motivasi belajar eksternal yang paling dominan dalam mempengaruhi hasil belajar Menggambar Teknik I. Hal ini disebabkan karena lingkungan keluarga merupakan lingkungan terdekat yang dimiliki oleh mahasiswa. Lingkungan keluarga juga merupakan tempat yang nyaman untuk berbagi cerita, wawasan, pengalaman, kesulitan dan kendala yang dihadapi mahasiswa dalam perkuliahan.

\section{KESIMPULAN, IMPLIKASI DAN SARAN}

\section{Kesimpulan}

Berdasarkan deskripsi, analisis, dan interpretasi data yang telah diuraikan pada bab-bab sebelumnya, dapat ditarik kesimpulan sebagai berikut :

a) Faktor motivsi belajar eksternal yang berasal dari faktor lingkungan keluarga yakni perhatian keluarga $(3,78)$, sarana dan prasarana belajar di rumah $(3,24)$ dapat mempengaruhi hasil belajar Menggambar Teknik I. Dan perhatian keluarga $(3,78)$ merupakan faktor motivasi belajar eksternal yang paling mempengaruhi hasil belajar Menggambar Teknik I.

b) Faktor motivasi belajar eksternal yang berasal dari faktor lingkungan kampus yakni cara dosen menyampaikan materi perkuliahan $\quad(3,28), \quad$ fasilitas menggambar di kampus $(3,38)$, organisasi mahasiswa di kampus $(3,43)$ dan keberadaan kampus $(2,90)$ juga dapat mempengaruhi hasil belajar Menggambar Teknik I.

c) Faktor motivasi belajar eksternal yang berasal dari lingkungan masyarakat yakni organisasi di masyarakat $(3,48)$ secara tidak langsung juga dapat mempengaruhi hasil belajar Menggambar Teknik I.

\section{Implikasi}

Berdasarkan hasil penelitian, tindak lanjut yang dapat diberikan adalah sebagai berikut :

a) Mahasiswa Program Studi Pendidikan Teknik Bangunan Jurusan Teknik Sipil UNJ perlu menyampaikan masalah dan kendala yang dihadapi dalam perkuliahan Menggambar Teknik I kepada keluarga.

b) Mahasiswa Program Studi Pendidikan Teknik Bangunan Jurusan Teknik Sipil UNJ perlu memaksimalkan sarana dan pra saran belajar Menggambar Teknik I di kampus.

Saran

Berdasarkan kesimpulan dan implikasi diatas dapat dikemukakan saran-saran sebagai berikut :

a) Diharapkan keluarga baik orang tua maupun kakak dan adik terus meningkatkan perhatian dalam perkembangan perkuliahan dan menyediakan kebutuhan belajar Menggambar Teknik I kepada 
mahasiswa, agar motivasi belajar Menggambar Teknik I tetap terjaga di rumah.

b) Sebaiknya pihak Jurusan Teknik Sipil UNJ, memonitor kelayakan ruang gambar tempat belajar Menggambar Teknik I secara berkala dan mengajak mahasiswa untuk selalu menjaga ruang belajar Menggambar Teknik I. Dengan terpeliharanya ruang gambar, dapat menumbuhkan motivasi belajar mahasiswa Menggambar Teknik I, yang akan diikuti dengan meningkatnya hasil belajar Menggambar Teknik I.

c) Mahasiswa Program Studi Pendidikan Teknik Bangunan Jurusan Teknik Sipil UNJ, diharapkan mampu berperan aktif dalam mengikuti kegiatan organisasi di lingkungan masyarakat untuk meningkatkan diri agar menjadi pribadi yang lebih baik.

\section{DAFTAR PUSTAKA}

Agustin. 2008. http://pengaruh-faktoreksternal-terhadapprestasi-belajar-siswadalam-mata-pelajaranekonomi.html (diakses pada 10 November 2011)

Anonimus. 2007. Buku Pedoman Akademik 2007-2008. UNJ Jakarta.

Arikunto S. 2001. Dasar-dasar Evaluasi Pendidikan. Jakarta: Bumi Aksara.

2006. Prosedur Penelitian
Pendekatan Praktek.
Jakarta: Rineka Cipta.

Chaeffer C. 2002. Bagaimana Membimbing Anak Secara Efektif. Jakarta : Restu Agung.

Djaali. 2007. Psikologi Pendidikan. Jakarta : PT. Bumi Aksara.

Dalyono M. 2005. Psikologi Pendidikan. Jakarta : Rineke Cipta.

[FT] Fakultas Teknik. 2002. Pedoman Teknis Penulisan dan Pelaksaan Ujian Skripsi, Komprehensif, Karya IImiah, dan Ketentuan Penyelenggaraan Tugas Akhir Program Diploma. Jakarta: Fakultas Teknik, Universitas Negeri Jakarta.

Fauziah S. 2010. Hubungan Antara Status Sosial Ekonomi Orang Tua Dengan Prestasi Belajar [Skripsi]. Jakarta: Fakultas Teknik, Universitas Negeri Jakrta.

Gunarsih Y. 2002. Asas-asas Psikologi Keluarga Idaman. Jakarta : BPK Gunung Mulia.

Hakim T. 2002. Belajar Secara Efektif. Jakarta : Puspa Suara.

Hamalik. Oemar. 2000. Psikologi Belajar dan Manager. Bandung: Sinar Baru Algessindo.

Hidayat, Dede Rahmat. 2009. IImu Prilaku Manusia. Jakarta : Trans Infimadia.

Prayitno. Elida. 2001. Motivasi dalam Belajar. Jakarta: PPLPTK Depdikbud. 
Purwanto. 2003. Dasar-Dasar Gambar Teknik. Jakarta: CV Media.

Purwarso Y. 2010. Motivasi Mahasiswa Program Studi Pendidikan Teknik Sipil Menjadi Guru SMK [Skripsi]. Jakarta: Fakultas Teknik, Universitas Negeri Jakarta.

Rafli. Zainal, dkk. 2008. Buku Pedoman Akademik 2008-2009. UNJ Jakarta.

Riduwan. 2008. Metode \& Teknik Menyusun Tesis. Cetakan ke-1. Bandung: Alfabeta.

Sardiman. A.M. 2001. Interaksi dan Motivasi belajar Mengajar. Jakarta: Rajawali Pers.

Siahaan, H. 1990. Peranan Ibu Bapak Dalam Mendidik Anak. Bandung: Angkasa.
Siregar, dkk. 2007. Buku Ajar Teori Belajar dan Pembelajaran. Jakarta: UNJ

Slameto. 2003. Belajar dan Faktor-faktor yang Mempengaruhinya. Jakarta: Rineka Cipta.

Sujanto. Agus. 2003. Psikologi Kepribadian. Jakarta: Bumi Aksara.

Sudjana. 2002. Metoda Statistika. Bandung: Tarsito.

Syah. M. 2000. Psikologi Pendidikan. Bandung: Rosdakarya.

_. 2003. Psikologi Pendidikan Dengan Pendekatan Baru. Bandung: Rosdakarya

Winkel WS. 1995. Psikologi Pengajaran. Jakarta: Grasindo. 